\title{
PRINCIPLES FOR THE DESIGN OF DIGITAL OCCUPATIONAL HEALTH SYSTEMS
}

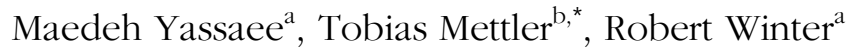 \\ ${ }^{a}$ University of St. Gallen, Institute of Information Management, Muiller-Friedberg-Strasse 8, CH-9000 St. Gallen, Switzerland \\ ${ }^{\mathrm{b}}$ University of Lausanne, Swiss Graduate School of Public Administration, Rue de la Mouline 28, CH-1022 Chavannes-près-Renens, Switzerland
}

Citation. Yassaee M, Mettler T, Winter R (2019). Principles for the design of digital occupational health systems. Information and Organization, 29(2), 77-90, https://doi.org/10.1016/j.infoandorg.2019.04.005

\begin{abstract}
There is a growing body of literature that addresses the importance of health and wellbeing in the workplace, and the effectiveness of corporate wellness programs. Following advancements in low-cost and unobtrusive computing technology, an emerging trend in corporate wellness programs is to offer wearable devices to employees. These devices monitor employees' physiological and environmental conditions in order to improve their awareness of their personal health. In addition, organizations can harness the aggregated anonymized data provided by such technology to investigate ways of improving the work environment. However, promoting digital health monitoring systems introduces new dynamic interactions between the social actors and technology. Three main categories of strain caused by the use of these systems in a work environment are value tensions (privacy vs. wellbeing); action tensions (work vs. leisure activities), and role tensions (leisure vs. work roles). Based on an analysis of these tensions, design principles for digital occupational health systems are derived that minimize strain and have much bigger chances to be accepted and thus to create value for all stakeholders. Consequently, this study follows the design science research paradigm to derive design principles.
\end{abstract}

Keywords. Digital occupational health, design principles, design science, health prevention, occupational health, well-being. 


\section{Introduction}

The modern workforce is steadily shifting to be less healthy than in years past. Workrelated accidents and the transmission of diseases are increasing (Wilson \& Sharples, 2015); there has also been a general upsurge in obesity and lack of exercise in modern society (Maikala, et al., 2014). Employees are older, and therefore at higher risk of ageassociated disease and disability (Maikala, et al., 2014). Finally, the workforce continues to facing an increasing level of work-related stress and other psychosocial risks (Nieuwenhuijsen, Bruinvels, Frings-Dresen, \& M, 2010). It is well established that psychosocial factors contribute significantly to the development and trajectory of chronic diseases (Ski, Thompson, \& Castle, 2016). Aside from personal and community costs, chronic ailments are responsible for a significant economic burden on employers. Costs include absenteeism and loss of productivity as well as treatment-related expenses for companies that subsidize health insurance for their employees (Sparks, Faragher, \& Cooper, 2001).

To help improve employees' health and control the cost of medical care, a growing number of companies have committed to providing wellness programs (Berry, Mirabito, \& Baun, 2010). A budding trend in corporate wellness programs is to offer personal health monitoring systems (PHMS), such as fitness trackers that offer employees psychosocial support (Fingas, 2015; Giddens, Gonzalez, \& Leidner, 2016; Olson, 2014; Vyas, et al., 2015; Mettler \& Wulf 2019). These devices can improve workers' selfconsciousness and prevent health-related risks. By harnessing the aggregated data generated by employees through the use of these devices, employers can identify behavioral patterns and environmental factors that impact health and wellbeing at work (Mathur, Van den Broeck, Vanderhulst, Mashhadi, \& Kawsar, 2015).

Although PHMS adoption has been studied in private settings (Sun \& Qu, 2015), corporate adoption of such systems has distinct yet under-investigated characteristics. For example, sensitive and highly personal health-related information collected in a nonhealth context may jeopardize an employee's privacy (Pozzi, Pigni, \& Vitari, 2014). In this study, we use the term "digital occupational health system" (DOHS) to refer to PHMS that are implemented in an occupational context and as such may generate certain conflicts as the material and social become pervasively entangled (Jonsson, Holmström, \& Lyytinen, 2009). 
However, in most countries organizations may not be able to force their employees to use these technologies due to confidentiality and other legal concerns (Lavallière, Arezes, Burstein, \& Coughlin, 2015). Therefore, the ability of DOHS to successfully promote workforce health and wellbeing is highly dependent upon employees' voluntary adoption and effective use. If employers cannot gain the trust of their workers regarding their use intentions, it could hamper the overall level of acceptance (Guo, Zhang, \& Sun, 2016; Pavlou, 2003). Therefore, employees' perceptions of the privacy risk posed by DOHS is a primary factor that needs to be managed and addressed in their design and implementation.

Even if employers motivate employees to use DOHS (e.g. by guaranteeing trustworthy data governance or offering financial incentives), the adoption of this class of system may soften boundaries between work and private activities and roles, thereby causing some social conflicts like action tensions (clashing work vs. leisure activities), and role tensions (self-contradictory leisure vs. work roles). Despite the goal of DOHS is to manage and reduce psychosocial risk factors, related social conflicts could actually provoke stress in the work environment. Work stress can cause employee burnout (Fisher \& Gitelson, 1983) and diminished organizational commitment and performance (Jackson \& Schuler, 1985). Therefore, it would be beneficial to identify approaches to managing and preventing these negative impacts.

Markus et al. (2002) explained that, when a class of technology has characteristics distinct from those of the more familiar types of systems (in our case, PHMS); a novel set of design principles may be required. Therefore, to determine DOHS's distinct characteristics related to technology, user, and organizational context, we explore the following research question:

What are the principles applicable to the design of DOHS that minimize social tensions at the workplace?

The remainder of the paper is organized as follows. In Section 2, we discuss the conceptualization and identification of design principles from a design science research perspective. In Section 3, we present our development of DOHS design principles. Section 4 outlines implications for information systems research and practice as well as discussing limitations and future work. This discussion is followed by the conclusion in Section 5 . 
Design science research (DSR) has been acknowledged as a legitimate approach to Information Systems (IS) research and practice (Gregor \& Hevner, 2013; Hevner \& Chatterjee, 2010; Winter, 2008). The DSR approach is based on a problem-solving paradigm and aims at designing purposeful artefacts; that is innovative, useful, generic or contextualized solutions to relevant design problems (Hevner, March, Park, \& Ram, 2004; Winter \& Baskerville, 2010). DSR artefacts should not be limited to solving specific problems in specific organizations, but emphasize the creation of solutions to "classes of problems" (Winter, 2008) and/or the exploration of contextual adaptations (Mettler, 2018; Sein, Henfridsson, Purao, Rossi, \& Lindgren, 2011) as well as social impacts of (detrimental) designs (De Leoz \& Petter, 2018). Thus, DSR produces both "meta-artefacts" such as design principles, technological rules, design theories, and patterns, as well as "instantiated artefacts" such as IT-reliant systems, situational models, and pragmatic design and evaluation methods (Göran Goldkuhl \& Lind, 2010; Gregor \& Hevner, 2013; Mettler, 2018; Mettler \& Rohner, 2009).

As our research question suggest, in this paper we will be focusing on design principles, being a crucial part of IS design theories. Design principles have been defined as "design decisions and design knowledge that are intended to be manifested or encapsulated in an artefact, method, process or system" (Gregor, 2002). By providing a generalized restriction of design freedom for interventions, design principles ensure that the intended behavior of the artefact is explicated in an accepted form (Purao, 2002). The high complexity and diversity of most socio-technical IS artefacts requires their design to be guided by principles instead of instantiated rules (Gregor \& Hevner, 2013; Markus, Majchrzak, \& Gasser, 2002). Gregor and Jones (2007) argue that "as the word "design" is both a noun and a verb, a theory can be about both the principles underlying the form of the design and also about the act of implementing the design in the real world (an intervention)". Principles of form and function are "design decisions and design knowledge that are intended to be manifested or encapsulated in an artefact, method, process or system" (Gregor, 2002). Principles of implementation are "the methodologies and tools used in the development of information systems" (Gregor, 2002).

Beyond focusing on the products of design - the artefacts - DSR is also concerned with systematizing and understanding the process of design that eventually yields that artefact (Peffers, Tuunanen, Rothenberger, \& Chatterjee, 2007; Walls, Widmeyer, \& El Sawy, 
1992). Regardless of existing DSR processes, two main strategies have been applied in the DSR process: meta-design and situational design (Göran Goldkuhl, 2004; Iivari, 2015).

The meta-design strategy is used to construct abstract design knowledge as a general solution concept and possibly instantiate it into a specific solution concept. Following this strategy, researchers have adapted two main approaches to deriving design principles: refinement of kernel theories in an IS design context and analogical design (Gregory \& Muntermann, 2014). Kernel theories stem from natural or social science, and supply a basis and explanation for the design (Gregor \& Jones, 2007; Walls, et al., 1992). Analogical design is an approach to transferring knowledge about one design situation to another design context (e.g. (Kärkkäinen \& Holmström, 2002). Instantiated IS artefacts developed from either of these approaches serve as a proof of concept, and not necessarily part of the process of generating design principles (Gregor \& Jones, 2007).

Situational design is an attempt to solve a specific problem by building a concrete IS artefact for a specific context, and distil the resulting knowledge into a general solution concept or body of abstract design knowledge (Iivari, 2015). To derive the design principles, ideation and prototyping follow this strategy, which first builds an IS artefact for a specific client context and, based on that experience, attempts to refine lessons into generalized design principles (Markus, et al., 2002; Sein, et al., 2011). The derived design principles following this strategy are the outcome of reconceptualizing and formalizing the learning from the specific solution instance into a class of solutions (Sein, et al., 2011).

To decide which strategy is more appropriate for a specific DSR project, identifying the form of DSR's contribution can be beneficial. However, identifying the form of DSR's contribution can be difficult because it depends upon "the nature of the designed artefact, the state of the field of knowledge, [and] the audience to whom it is to be communicated" (Gregor \& Hevner, 2013).

Gregor and Hevner (2013) created a knowledge contribution framework to assist researchers in understanding and positioning the contributions of DSR projects, depending upon problem and solution maturity. Based on this framework, this study would be categorized as an "exaptation DSR project" that is research that explores and or extends known solutions to new kinds of problems or contexts. The problem at hand is finding ways to foster the adoption of DOHS in an organizational setting, which poses 
unique challenges not present in the private and clinical contexts in which this type of system has previously been applied (Dvorak, 2008; H. Li, Wu, Gao, \& Shi, 2016). Conversely, the solution proposed in this research (the design principles) will be based on existing coping strategies (kernel theories) that serve to balance and minimize the action, role and value tensions. Therefore, grounded in kernel theories, we have followed the meta-design strategy to derive design principles.

The core issue in making the task of meta-design a research endeavor is determining how the design should be justified and validated (Göran Goldkuhl \& Lind, 2010). The validation and justification of principles, as abstract design knowledge, should be grounded theoretically, internally, and empirically (Göran Goldkuhl, 2004). Theoretical grounding involves the use of external theories and knowledge; these demonstrate the grounding of prescriptive design knowledge in explanatory theories. Internal grounding is control of internal cohesion and consistency in meta-design. Empirical grounding consists of observations of its utilization and effects.

The construction of design principles grounded in justificatory knowledge has been studied as steps in the process of developing IS design theories (ISDT) (Gregor \& Hevner, 2013) which Walls et al. (1992) defined as a prescriptive theory integrating normative and descriptive theories into design paths intended to produce more effective information systems. An ISDT has been separated into product and process components (Gregor \& Jones, 2007). The product component is concerned with the construction of design principles governing the blueprint or architecture of an IS artefact. The process component represents the design method for the IS artefact and integrates existing kernel theories that govern the design process (Beck, Weber, \& Gregory, 2013). The focus of this study is on product component, which is construction of design principles governing the DOHS architecture. Therefore, we emphasize one part of ISDT which is explanatory in that it "prescribes principles that relate requirements to an incomplete description of an object" (Baskerville \& Pries-Heje, 2010).

Niehaves and Ortbach (2016) provided a framework for justifying the consistency and cohesion of the explanatory ISDT. This framework is concerned with both descriptive and prescriptive functions of principles. This framework consists of two main models: inner and outer. At the core is the inner model, which is the theoretical grounding of the principles. It represents the justificatory knowledge that constitutes the kernel (a concept taken from the natural or social sciences) (Simon, 1996) or practitioner-in-use 
theory (Sarker \& Lee, 2002). The inner model consists of the explanatory aspects of the design principles, along with the dependent and independent variables and the causal relationships among them. It seeks to explain why the artefact creates certain effects, and that certain actions are expected (Niehaves \& Ortbach, 2016). The outer model is concerned with constructive aspects and prescriptive elements. It deals with the relationships among the latent variables, kernel theory constructs, and manifest metarequirements and meta-design (the prescribed actions). Meta-design is the manifestation of independent latent variables in the inner model, which define the design items or the instantiated IS artefact. To assess whether the meta-requirements are fulfilled in metadesign, evaluation criteria are required. Different evaluation criteria addressing the same theory may lead to different results and must be selected carefully (Niehaves \& Ortbach, 2016).

Identification of the meta-requirements (or class of goals) is dependent upon the structure of the problem at hand and one's understanding the scope and purpose of the design principles (Gregory \& Muntermann, 2014; Mandviwalla, 2015); it directs the process of searching for relevant concepts towards the justificatory knowledge of the inner model. The next step is to locate the constructs and concepts of the kernel theories within the context of the problem (IS design). During the process of deriving the design principles, a transition from the kernel theories to the context of IS design results in an increase in specialization (or concretization) of the theories' constructs (Kuechler \& Vaishnavi, 2012). Grounded in the contextualized constructs of the inner model, within the outer model the design principles "state that a particular class of artefacts will address a specific class of goals and do not express why this is the case." The outcome is a set of testable propositions that provide a rationale for the proposed design principles by relating the meta-design to meta-requirements (Gregory \& Muntermann, 2014).

For empirical grounding, the propositions can be tested based on their application in practice, as well as their ability to effectively satisfy the meta-requirements. The applicability of the principles can be tested based on criteria validated by the artefact's users (in our case, IT systems designers and managers in organizations willing to adopt DOHS), who will apply the principles. Users unwilling to employ the principles who have objections to their usability can become a critical impediment to success. To test the effects of the proposed principles, an IS artefact can be instantiated following the design principles, and then tested if the instantiated IS artefact satisfies the meta- 
requirements. However, one should remember that this method of evaluation embraces all of the complexities of human practice in real organizations. To the extent that this evaluation is affected by confounding variables or misinterpretation, the evaluation may not be precise or even trustworthy with regards to the design principles' effect (PriesHeje, Baskerville, \& Venable, 2008). Therefore, "it is impossible to prove its effect conclusively, but it can be tested in context, which in turn can lead to sufficient supporting evidence" (van Aken, 2004).

Through different episodes of testing the design principles, we can move towards a satisfactory state where further testing and input only leads to marginal adjustment, defined as saturation (Carlsson, Henningsson, Hrastinski, \& Keller, 2011). The evaluation strategy followed in a DSR project or program may differ according to the needs and resources available to that project or program (Venable, Pries-Heje, \& Baskerville, 2016). Following the DSR evaluation's strategic framework developed by (Pries-Heje, et al., 2008), each episode of evaluation can be performed either ex ante (before) or ex post (after) the design of IS artefact (or its corresponding design theory), as well as artificially or naturalistically. Artificial evaluation is not limited to a specific technology solution in experimental settings, but instead can include simulated settings where the technology solution (or its representation) can be studied under substantially artificial conditions. Naturalistic evaluation explores the performance of a constructed solution technology in a real environment (i.e., within the organization). It has been argued that artificial evaluation is appropriate for testing design propositions (Walls et al., 1992). This is due to the fact that in a naturalistic setting, it is difficult and costly to discern the effects of many confounding variables (Pries-Heje, et al., 2008). The testable propositions can be evaluated by means of one particular instantiation, and designers have a certain amount of freedom that can influence an audience's perceptions (Niehaves \& Ortbach, 2016).

Based on the specialization of the Niehaves and Ortbach (2016) framework to design principles, the descriptive and prescriptive statements of the design principles, which should govern the DOHS architecture, are presented in the following section. Before presenting the DOHS design principles, we illustrate our research process and introduce our evaluation design.

\section{DOHS Design Principles}

Based on the socio-technical IS design theory development approach proposed by Carlsson, et al. (2011)) and following De Loez and Petter's (2018) call for integrating the 
social impacts of artefacts, we conduct four main activities for constructing DOHS design principles: (1) identifying problem situations and desired outcomes, (2) reviewing extant theories, knowledge and data, (3) proposing/refining design theory and knowledge, and (4) testing design theory and knowledge.

For our research, this approach was appropriate because of its methodological support to develop design theory by following the meta-design strategy. This approach is built on evidence from extant design science processes in IS (e.g., Hevner, et al., 2004; Peffers, et al., 2007) and management (e.g., van Aken, 2004; van Aken \& Romme, 2009).

(1) Identifying scope, problem situations and the desired outcomes. The result of this activity is the identification of meta-requirements. The process of requirements identification for DOHS design principles are presented in our previous study (blind for review), these requirements are briefly defined in this study.

(2) Reviewing extant theories, knowledge, and data. Corresponding with the metarequirements, this activity is concerned with the identification of relevant theories of explanatory statements in the body of knowledge. Within the social science literature, a variety of theories have been employed in an effort to gain a deeper understanding of the factors that increase the trust in a given social exchange process. For the privacy and trust requirement, those theories are adapted to the context of DOHS. For the case of work life integration, the existing theories and approaches in both social science and human computer interaction (HCI) literature are adapted to DOHS context.

(3) Proposing/refining design principles. With this activity, we try to contextualize the explanatory statements for the design of DOHS. Based on the latent explanatory statements, design propositions are formulated as a class of activities predicting satisfaction with the meta-requirements.

(4) Testing design principles. In this study, an ex ante artificial evaluation is conducted to test the applicability of design propositions in practice. This evaluation will potentially reduce cost by repairing technical issues before any instantiation or implementation of the design propositions in DOHS. At this stage, an expost naturalistic evaluation would be extremely difficult to conduct. First, any intervention in a work setting with an untested design proposition would be logically problematic (Carlsson, et al., 2011). Second, studying the actual effect of an instantiated DOHS on employees' health and wellbeing and, respectively, on organizational performance would be a lengthy process 
which due to the novelty of the application of these systems in corporate setting is not yet possible.

\subsection{Design Principle for Managing the Value Tension}

Value tension has been defined in the literature as situations in which two values that are both important come into conflict (J. Stewart, 2006). While in some situations there is no other option than to choose one value over the other, it is often helpful to think of ways in which both values can be honored (J. Stewart, 2006). The application of DOHS might create value tension for employees between privacy and wellbeing. While the personalization of data offers the value of health and wellbeing enhancement and a greater level of security at work, the possibility that personal data might be used by the employer or a third party for discriminatory purposes threatens employees' privacy. It has been argued that employees' perceptions of privacy risk could lessen the technology acceptance (Guo, et al., 2016; Pavlou, 2003). Thus, if suggestions are to be made regarding DOHS-related privacy concerns, the first requirement must be:

Requirement 1: Reduce employees' sense of privacy related risks when using employer-provided DOHS.

Individuals' decisions regarding privacy involve a complex psychological process that engages multiple considerations (Y. Li, 2012). Consequently, a variety of theories have been employed in the effort to gain a deeper understanding of the factors influencing individuals' privacy-related perceptions (Y. Li, 2012). Grounded in the concept of information privacy, we sought kernel theories designed to decipher institutional factors influencing individuals' perceptions of information privacy risk.

Procedural fairness (Lind \& Tyler, 1988), social presence (Reis \& Shaver, 1988), and social response (Short, Williams, \& Christie, 1976) theories have been adopted to illustrate the impact of institutional factors on individuals' privacy concerns. These institutional factors are interconnected. For example, procedural fairness helps to establish social contracts, and both social presence and social contracts (i.e., trust) encourage customers' social response and self-disclosure of personal information.

Procedural fairness, also known as procedural justice, is a perspective on relationships of social exchange. It refers to an individual's perception that a particular activity in which they are participating is conducted fairly (Lind \& Tyler, 1988). Culnan and Armstrong (1999) found that the following constructs facilitate fairness: informing the 
individual for their personal data collection, use, dissemination, and maintenance; seeking his or her consent for that collection, use, dissemination, and maintenance; and providing mechanisms for appropriate access, correction, and redress. It has been argued that procedural fairness is a strong predictor of organizational trust and commitment, which in turn enhances employees' motivation to work in favor of the organization (Cohen-Charash \& Spector, 2001). Ambrose and Alder (2000) have argued that when organizations utilize monitoring systems that lead to perceptions of fairness, employees respond more positively. The theory further suggests that even in situations where the potential outcomes are not favorable to the individuals, they are still less likely to feel dissatisfied if they believe that the underlying procedure is fair (Folger \& Bies, 1989; Greenberg, 1987; Lind \& Tyler, 1988). Table 1 demonstrates the explanatory statement, design proposition.

\begin{tabular}{|l|l|}
\hline $\begin{array}{l}\text { Explanatory } \\
\text { Statement }\end{array}$ & The greater the perception of procedural fairness, the more trust. \\
\hline Design Proposition & $\begin{array}{l}\text { DOHS should feature notice, consent, and controllability of the } \\
\text { employees' personal information to reduce employees' privacy-based } \\
\text { risk perception. }\end{array}$ \\
\hline
\end{tabular}

Table 1. Social fairness principle

Social response theory states that during a social exchange relationship people will engage in self-disclosing behavior if they are the recipient of a similar disclosure from their partner (another person or organization) (Reis \& Shaver, 1988). The tendency to disclose in response to a prior disclosure is known as the principle of reciprocity (Gouldner, 1960). Reciprocity involves a feeling of obligation to divulge something in return for something similar the individual receives; it is one of the guiding forces of human interaction. In order to achieve this reciprocity for the case of DOHS, it is important for employers to openly communicate and share how they are going to use the data for the benefit of employees - and not against them - and regularly communicate the outcome of their DOHS use; they may influence their employees' privacy risk perception. Table 2 presents the explanatory statement, design proposition. 


\begin{tabular}{|l|l|}
\hline $\begin{array}{l}\text { Explanatory } \\
\text { Statement }\end{array}$ & $\begin{array}{l}\text { Employee will engage in self-disclosure if they are the recipient of a } \\
\text { similar disclosure from their organization. }\end{array}$ \\
\hline Design Proposition & $\begin{array}{l}\text { DOHS should feature a medium that facilitates an open sharing and } \\
\text { communication of an organization's approach to their use of DOHS, } \\
\text { to reduce employees' privacy-based risk perception. }\end{array}$ \\
\hline
\end{tabular}

Table 2. Social response principle

Social presence refers to a measure of the awareness of other persons in a communication interaction. The theory suggests that for a given task, the level of social presence should match the level of interpersonal involvement needed for that task. Social presence theory (Short et al., 1976) proposes that the elevated level of social presence through richer media increases trust and approval of the content communicated (Guerin, 1986). For the case of privacy risk perception, people generally feel a stronger level of trust when they engage in face-to-face or video-supported communication because it allows them to use signs such as eye contact, body gestures, and facial expressions. Table 3 synthesizes the explanatory statement of social presence kernel theory and its applicable design proposition.

\begin{tabular}{|l|l|}
\hline $\begin{array}{l}\text { Explanatory } \\
\text { Statement }\end{array}$ & $\begin{array}{l}\text { The varying capacities of different communications media (media } \\
\text { richness) facilitates different levels of intimacy for employees. }\end{array}$ \\
\hline Design Proposition & $\begin{array}{l}\text { Richer media (e.g., human embodiment or videos) should be used } \\
\text { instead of text-based privacy statements to reduce employees' privacy- } \\
\text { based risk perception. }\end{array}$ \\
\hline
\end{tabular}

Table 3. Social presence principle

\subsection{Design Principle for Managing the Action Tension}

In addition to privacy risks, adoption of DOHS in organizational setting may cause tensions between work and leisure activities. While employees interact with DOHS through intentional acquisition (for instance, by checking their performance on their personal dashboard), they can also receive information without actively looking for it. This passive interaction (alerts, recommendations, re-minders, etc.) could demand nonwork activities (e.g., taking a break, drinking water, competing with colleagues, etc.), and thus would interrupt work-related tasks. Task interruptions caused by interactions with DOHS could cause technostress in the work environment (Mark, Gudith, \& Klocke, 
2008). Technostress is the stress experienced by end users in organizations as a result of their use of IT systems (Ragu-Nathan, Tarafdar, Ragu-Nathan, \& Tu, 2008). Studies have illustrated the negative impact of technostress on a person's wellbeing state (Zijlstra, Roe, Leonora, \& Krediet, 1999). The excessive and repetitive interruptions are also distractive which add to cognitive effort may in fact lead to the almost automatic dismissal of most alerts, including those that are safety-critical (Feldstein, et al., 2004; Wipfli \& Lovis, 2010). To avoid DOHS-related work interruptions, the following requirement is formulated:

Requirement 2: Reduce DOHS excessive interactions with employees to avoid work interruptions.

The justificatory knowledge informing the testable proposition for addressing this requirement is the "Interruption Evaluation Paradigm"; this paradigm is applied in human computer interaction (HCI) (Dabbish \& Baker, 2003; Grandhi \& Jones, 2010; Milewski, 2006; Szóstek \& Markopoulos, 2006).

Researchers working from this perspective argue that the interruptions should be managed based on factors of social or cognitive context of the person being interrupted, as well as factors related to the content of the interruption (the relational context). It means the degree of alert-intrusiveness can be adjusted according to the alert's level of importance, allowing only the most severe warnings to interrupt work (Grandhi \& Jones, 2010). In addition, rules that trigger alerts can also be filtered and prioritized to suppress low-severity warnings by using more sophisticated algorithms that integrate the receiver's cognitive and social context into the decision logic. Cognitive context has been defined as all aspects that encompass the receiver's cognitive level of involvement in a task (Grandhi \& Jones, 2010). Social context includes all aspects encompassing the receiver's immediate environment, as understood in a social sense; this would include the place the individual is in, people present within that place, and the social nature of the activity occurring at that location (Grandhi \& Jones, 2010). Table 4 summarizes the application of this paradigm in DOHS design.

\begin{tabular}{|l|l|}
\hline Explanatory Statement & $\begin{array}{l}\text { Any interruption has different level of impact on employee } \\
\text { based on his/her social, cognitive and relational context. }\end{array}$ \\
\hline Design Proposition & $\begin{array}{l}\text { DOHS should support the automated and manual prioritization } \\
\text { and filtering of interactions based on different levels of severity } \\
\text { of the content (the relational context) and the employee's social }\end{array}$ \\
\hline
\end{tabular}




\begin{tabular}{|l|l|}
\hline & $\begin{array}{l}\text { and cognitive context, in order to reduce unnecessary } \\
\text { interruptions. }\end{array}$ \\
\hline
\end{tabular}

Table 4. Interruption management principle

\subsection{Design Principle for Managing the Role Tension}

Another risk factor of integrating work and private life through DOHS is role tension. Role tension occurs as the result of incompatibilities among the many demands of an employee's work environment, such as contradictory expectations, incompatibilities among certain organizational practices, or inadequate resources for performing tasks (Rizzo, House, \& Lirtzman, 1970). The adoption of DOHS could result in a role tension in which an employee has to find a balance between conflicting work and leisure demands. Using DOHS at work means an employee would use worktime to take care of his or her wellbeing, which is not a defined work task. Evidence has indicated that role tension leads to dysfunctional workers and negative organizational consequences (Bostrom, 1980). This leads to the following requirement:

Requirement 3: The design and implementation of DOHS should support coping strategies for role tensions.

Role process theory and the model of coping: Following Levinson's (1959) role process theory, Hall (1972) proposed two coping mechanisms for role tension that intervene in the role process: structural and personal role redefinition. Structural role redefinition can be accomplished through "communication with [the] role sender and negotiating a new set of expectations, which will be mutually agreed upon." Personal role redefinition can be achieved through an attempt to change one's attitude towards role expectations by avoiding overlapping roles or setting priorities among and within them. Table 5 illustrates the explanatory knowledge behind structural role redefinition and their relevant design propositions as well as exemplary scenarios. Table 6 summarizes the design proposition and its respective explanatory knowledge.

\begin{tabular}{|l|l|}
\hline $\begin{array}{l}\text { Explanatory } \\
\text { Statement }\end{array}$ & $\begin{array}{l}\text { Structural role redefinition as a conflict coping behavior, involves } \\
\text { altering external, structurally imposed expectations relative to } \\
\text { employees' position }\end{array}$ \\
\hline Design Propositions & $\begin{array}{l}\text { Organizations should communicate their expectations regarding how } \\
\text { long employees should interact with DOHS to avoid role tensions. }\end{array}$ \\
\hline
\end{tabular}


Table 5. Structural role redefinition principle

\begin{tabular}{|l|l|}
\hline $\begin{array}{l}\text { Explanatory } \\
\text { Statement }\end{array}$ & $\begin{array}{l}\text { Personal role definition as a conflict coping behavior, involves } \\
\text { changing employees' expectations and perception of own behavior } \\
\text { in a given position. }\end{array}$ \\
\hline Design Proposition & $\begin{array}{l}\text { DOHS should limit any access outside the acceptable range. During } \\
\text { worktime, employees' interaction with DOHS should be limited to } \\
\text { necessary alerts to avoid role tensions. }\end{array}$ \\
\hline
\end{tabular}

Table 6. $\quad$ Personal role redefinition

\subsection{Testing the Applicability of the identified Design Principles}

\subsubsection{Research Context}

The applicability of design principles is assessed in the context of a DOHS design project, Active@Work. This project was funded by the European Commission and the Swiss State Secretariat for Education, Research, and Innovation. This work supports senior employees in their effort to efficiently perform job-related tasks without risking their health. The solution is an innovative data integration infrastructure of wearable devices for context-aware surveillance (cf. Figure 1), meaning that data are analyzed according to two main dimensions: the health status of each individual and the environmental conditions of the workplace. The main goal of this solution is proper management of the negative impacts of aging and work-related health issues such as stress and fatigue - both physiological and psychological - on employees' performance and productivity.
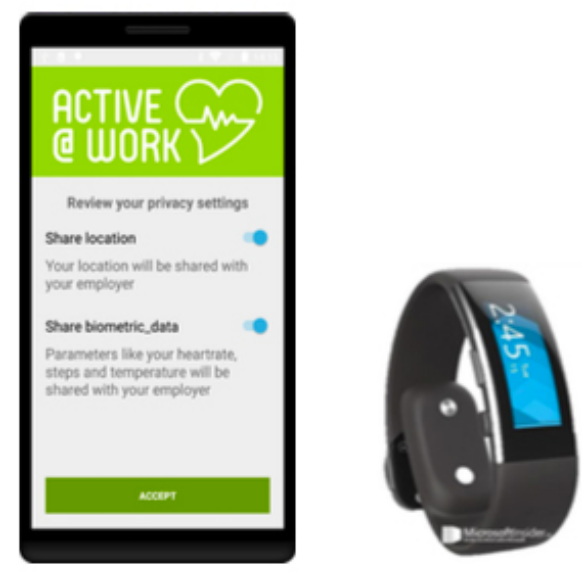

Figure 1. Active@Work mobile app and fitness tracker for collecting physiological data of employees 


\subsubsection{Data Collection}

In order to confirm proof of the proposed design principles applicability in the field of DOHS, two focus groups have been conducted. The focus group technique is useful as an exploratory method when little is known about the phenomenon as well as a confirmatory method to test hypotheses (D. W. Stewart, Shamdasani, \& Rook, 2007). Tremblay et al. (2010) have argued that the focus group "is an effective technique to be used to both refine and evaluate the design science artefact”. To design and conduct the focus groups, we followed the process proposed by Tremblay et al. (2010), which provides guidance for researcher to adapt focus group technique to design science research. Following this process, the first step to effectively design the focus groups in DSR is to identify the goal clearly. There can be two main and yet different goals to conduct focus groups in design science research: (1) exploratory focus groups (EFGs) to achieve incremental improvements in artefact design and (2) confirmatory focus groups (CFGs) to demonstrate the utility of the design in a field setting (Tremblay, et al., 2010). In this study, CFGs were conducted to demonstrate the applicability of DOHS design principles. The next step in this process is to identify the sample frame, which includes three main decisions: number of focus groups, the desired number of participants and where to recruit the participants. To decide the number of CFGs, following the guideline, one pilot focus group and two CFGs were conducted. The pilot focus group was conducted to help identify timing issues, refine the questioning route, and evaluate the moderator's style. The pilot focus group participants were the artefact designers. The pilot data were not used further for data analysis. To recruit the participants in the CFGs, one important criterion would be to ensure that participants are familiar with the research object under examination. Therefore, we selected two distinct groups of users of the principles, eleven Active@Work designers and six managers of the company piloting the project. The pilot company is an international IT service provider that offers end-to-end consulting, systems integration, and managed services. The next step in this process is to identify the moderator. For design research, in addition to specific personal skills, the moderator needs to have a clear understanding of the design artefact. Thus, in this study, the moderator was one of the artefact designers. However, we tried to avoid any personal bias in the presentation and being careful to not justify or defend our work by practicing different scenarios during the pilot focus group. 
The next step is to develop the questioning route. The questioning route is the agenda for the focus group (Tremblay, et al., 2010). In order to systematically prepare a questioning route, which covered all six principles, as well as to increase the understandability of the design propositions, we developed and documented possible scenarios for each design principle as "storyboards" (Appendix A). Storyboard is a design space for the narrative visualization of a user's interaction with the system and the critical contextual aspects, over time (Hackos \& Redish, 1998). Key features of storyboards include people, their actions, and emotions, as well as the depiction of time, inclusion of text, and level of detail (Truong, Hayes, \& Abowd, 2006). Using storyboards helps to direct the focus of the audiences to the scenario communicated and keeps them from being distracted by technical and logistical details. While there are many exclusive tools to develop storyboards, we used Microsoft PowerPoint, since it could provide us with many handy and simple features without causing any extra costs.

Since the participants of the focus groups were familiar with Active@Work, the focus groups were started by presenting the storyboards as a scenario of Active@Work adoption process by an organization. The main persona Nick is an employee of this fictitious organization, which his work life is going to be influenced by the introduction of Active@Work. Anna other persona in these storyboards is a manager responsible to launch Active@work in her department. Following the brief introduction, the discussion was guided by the presentation of each storyboard, which was complemented by the explanatory knowledge supporting it, as well as the prescriptive design propositions. The focus groups were centered on the participants' impressions of the design propositions and their assessments of the principles based on the three criteria proposed by Rosemann and Vessey (2008) to test the applicability of design artefact: importance, accessibility, and suitability. The participants also asked how the principles might be adjusted to better meet those criteria. To complement verbal feedback, evaluators were asked to rate all of the principles on a 1 to 5 scale, according to the three evaluation criteria. Each focus group lasted approximately ninety minutes; the focus groups were audiotaped; also, the moderator of the focus groups took notes. As with all such recordings, the participants were informed and their consent was requested. The recordings were transcribed verbatim. 


\subsubsection{Findings}

Social presence: most of the evaluators found this principle important, accessible, and suitable. However, one evaluator said: "even though I can see the importance of this scenario, there will be some employees who even if you tell them and explain it to them that you are not going to harm them, their pre-assumption is that use of such systems is for the benefit of the organization and not the employees. I would say it depends on the culture of the organization, at least in our company. Me, as a manager, I have such experience. However, I would say with this scenario that at least you could gain the trust of some employees."

To reinforce this scenario, evaluators added two main points. First, they said: "while such launching sessions are required, it can be helpful not only to talk about the privacy policy but also present the existing regulatory documents and inform employees about their rights." Second, in addition to presenting the privacy policy and informing participants about the legal responsibilities of the organization, it would be useful to talk about the benefits of employees using the system. "I would say that not only explaining how the organization is going to use the information but also presenting the potential benefits to employees [is important]. Benefits should be ahead of everything and [be used to] try to motivate them with other incentives." Other evaluators complemented this point by suggesting that the introduction of these systems should be an incremental process, starting with a pilot; then an effort should be made to display the benefits to the whole organization, and not only to the people involved in the pilot. Therefore, employers would gradually gain their employees' trust. "Before actual adoption of the system in a whole organization, it could be useful to have a pilot and people who were involved in this pilot could attend in this launching session and share the experiences and benefits they achieved by using the system, in an open discussion format."

Social response: all of the evaluators highly supported this scenario, emphasizing the importance of general transparency to the successful introduction of such systems in organizational settings. The evaluators again mentioned that scenarios like this might not result in full trust, but they are necessary for the incremental process of adopting such systems. "There are always some people who even if you show them what you do with the data, they think this is the part they are showing me but it is not everything."

For evaluators, this was one possible scenario that could lead to more transparency. " $I$ think that scenarios like this are important, at least in the beginning. It shows that 
organizations are willing to [earn] trust. The more transparency, the better." Returning to the importance of demonstrating the benefits of this system to employees, one evaluator commented: "This gives more transparency and transparency is trust. In addition, it is ... about bolding the benefits and showing the benefits to individuals. Like if you show them you are adapting the working environment to be a better place to work based on their data, then they can actually see the benefit."

However, even though the evaluators found this scenario important for gaining more trust, they were concerned with the feasibility from an organizational perspective. "If the company publicly announced their data and committed to report on this system, it would be an extra effort and responsibility; also, it would be an issue of liability, so maybe some companies would not commit to it." On the other hand, another evaluator highlighted the benefit of this scenario to their organization: "I think it is really useful for companies, because most companies need the wellbeing state of the art to show the insurance company or even for their social responsibility. I think it is even a good point to sell this product to companies, because a thing such as wellbeing state of the art is really getting more and more important."

Social fairness: the evaluators found this scenario to be the most vital of the options, specifically for reducing employees' concerns regarding privacy risks. "In my experience, to develop the bealthcare application, this is the thing that is always demanded by users. The other scenarios can help improve trust, but this one is vital. I share my information, but I should be sure that any time I wanted, I could easily close the door. This is the most important." However, evaluators said they could imagine that giving this complete power to users might reduce the value of the data to their employers. "Imagine if 20 employees are using the system and all restrict most of the measurements, then even aggregated data will not have value."

Adjusting the working environment: All of the evaluators agreed on the importance, accessibility, and suitability of this scenario from the company perspective. "As a team, we should be sure that there is no one spending three hours on this system. It should be limited. Do it at home or schedule it for another day. "However, from a user's perspective "it could limit [their] freedom". One evaluator highlighted the importance of the first part of the scenario (communicating the organization's expectations regarding the time that should be allocated to active interaction with system). "It is crucial, because then 
employees know that the company gave them this time and nobody will tell them anything or judge them. If it is communicated, it can facilitate the process."

Minimizing the simultaneous overlap of roles: The evaluators reached an immediate consensus with regards to this scenario. There was full agreement on the necessity of receiving alerts and recommendations from the system throughout the day, while active interaction with the system was limited. They found the quality of this scenario to be dependent upon the other scenarios related to interruption management.

Automated reduction of excessive alerting also received the full consensus of the evaluators. While putting the user in control of managing interruptions was found to be complementary to the latter scenario, the only concern they had was with ease of use: "it should be simple, the configuration. User-friendliness is the only thing [that] worries me."

\section{$4 \quad$ Discussion}

In this study, we argue that the incorporation of PHMS in employee wellness programs has given rise to new user requirements; these requirements demand an extended set of design principles to be observed when developing and implementing DOHS. The principles derived in this study can be expected to reduce social tensions caused by adoption of DOHS in organizational settings, in particular, value tensions (privacy vs. security and wellbeing), action tensions (work vs. leisure activities), and role tensions (leisure vs. work roles). The table 7 summaries the six design principles derived in this design science research.

\begin{tabular}{|l|l|l|}
\hline Design Req. & Design Principle & Statement \\
\hline $\begin{array}{l}\text { Value Tension } \\
\text { Coping }\end{array}$ & Social Fairness & $\begin{array}{l}\text { DOHS should feature notice, consent, and } \\
\text { controllability of the employees' personal information } \\
\text { to reduce employees' privacy-based risk perception. }\end{array}$ \\
\hline $\begin{array}{l}\text { Value Tension } \\
\text { Coping }\end{array}$ & Social Response & $\begin{array}{l}\text { DOHS should feature a medium that facilitates an open } \\
\text { sharing and communication of an organization's }\end{array}$ \\
\hline
\end{tabular}




\begin{tabular}{|l|l|l|}
\hline Coping & & $\begin{array}{l}\text { approach to their use of DOHS, to reduce employees' } \\
\text { privacy-based risk perception. }\end{array}$ \\
\hline Value Tension & Social Presence & $\begin{array}{l}\text { Richer media (e.g., human embodiment or videos) } \\
\text { should be used instead of text-based privacy } \\
\text { statements to reduce employees' privacy-based risk } \\
\text { perception. }\end{array}$ \\
\hline Consion & $\begin{array}{l}\text { Interruption } \\
\text { Management }\end{array}$ & $\begin{array}{l}\text { DOHS should support the automated and manual } \\
\text { prioritization and filtering of interactions based on } \\
\text { different levels of severity of the content the relational } \\
\text { context) and the employee's social and cognitive } \\
\text { context, in order to reduce unnecessary interruptions. }\end{array}$ \\
\hline Role Tension & $\begin{array}{l}\text { Structural Role } \\
\text { Redefinition }\end{array}$ & $\begin{array}{l}\text { Organizations should communicate their expectations } \\
\text { regarding how long employees should interact with } \\
\text { DOHS to avoid role tensions. }\end{array}$ \\
\hline Role Tension & $\begin{array}{l}\text { Personal Role } \\
\text { Redefinition }\end{array}$ & $\begin{array}{l}\text { DOHS should limit any access outside the acceptable } \\
\text { range. During worktime, employees' interaction with } \\
\text { DOHS should be limited to necessary alerts to avoid } \\
\text { role tensions. }\end{array}$ \\
\hline
\end{tabular}

Table 7. DOHS design principles

The two focus groups conducted in this study in addition to the empirical validation of the applicability of DOHS principles leads us to perceive the DOHS adoption in work environment as an incremental process of motivating employees. While, the proposed interventions cannot immediately eliminate the privacy and work life integration risk perceptions, they are assumed as prerequisites for introducing the DOHS in organizational setting by DOHS system designers and managers adopting the system.

\subsection{Theoretical considerations}

This study contrasts the use of personal health monitoring systems, which have been primarily applied and tested in clinical and private context, to the organizational context (i.e., the unknown problem). The solution proposed in this study (the design principles) is based on existing coping strategies (kernel theories) that serve to counter or balance the value, action and role tensions (i.e., the known solution). Thereby, this exaptation 
research contributes to the descriptive knowledge base by building a set of principles useful to the design and implementation of DOHS systems in organizational settings. In order to discover and explore the relationships among the important concepts relevant to the design principles presented in this study, we adopted the framework established by Niehaves and Ortbach (2016). This framework allowed us to assess the design principles as a part of explanatory design theory and enabled a better understanding of the relationships among the various manifest design decisions and kernel theory constructs. Our work provides an instantiation of this framework, illustrating the possibility of using this comprehensive outline to develop design principles as a part of an explanatory design theory. By adopting this framework, the highly abstract space of potential problem solutions suggested by kernel theories (e.g. theory of role process, social presence) was systematically transitioned to the DOHS context. For instance, in this study one of the meta-requirements was to minimize the end users' privacy concern. To inform our design, we sought kernel theories that were found to have impact on institutional factors on individuals' privacy concerns. Social presence theory adopted in computer mediated communication has shown positive impact on minimizing the privacy concerns (effect). The two major factors causing the social presence are human embodiment and media richness (cause). Therefore, by contextualizing these causes and effects to our problem, we defined our explanatory statement: the varying capacities of different communications media (cause) facilitates different levels of intimacy for employees (effect). On the basis of this statement, we have defined the following design principle: Richer media (e.g., human embodiment or videos) should be used instead of text-based privacy statements of DOHS to reduce employees' privacy-based risk perception. It is important to take into account that the design principles can only govern the design artifact architecture (in our case DOHS) and the designers have a certain amount of freedom to choose from a set of alternatives and are thus subject to reasoned preferences (Niehaves \& Ortbach, 2016). Therefore, our operationalization of the social presence and other principles into the design items (visualized by storyboards) are only possible ways to instantiate the principles.

\subsection{Practical implications}

The presented findings show an engaged style of research that is framed within a pragmatic philosophy (Mathiassen \& Nielsen, 2008). As such, contributions to the knowledge base are not necessarily restricted to (theoretical) explanations and to understanding, but can also have normative or practical character (Goran Goldkuhl, 
2012; Gregor \& Hevner, 2013). From this practical perspective, our study could offer organizations currently using or considering implementing DOHS as part of their occupational wellness program some new insights. While, the scientific community has begun to show interest in the design and implementation of systems for improving employees' health and wellbeing, primarily by examining digital health monitoring technologies (e.g., Ara, et al., 2011; Kritzler, et al., 2015; Olguín, et al., 2009) the focus has primarily been on technical aspects. There is a relatively small body of literature that has addressed the relevant social elements (e.g., Christophersen, Mørck, Langhoff, \& Bjørn, 2015; Lavallière, et al., 2015; Lavallière, Burstein, Arezes, \& Coughlin, 2016; Mathur, Broeck, Vanderhulst, Mashhadi, \& Kawsar, 2015; Mathur, Van den Broeck, et al., 2015; Moore \& Piwek, 2016). Overall, these studies suggest that the introduction of wearable tracking devices to improve employees' wellbeing in the work environment will bring unforeseen challenges; all first and foremost emphasized employees' privacy concerns (Marabelli, Hansen, Newell, \& Frigerio, 2017). However, these works only discussed challenges and stopped short of providing solutions. Our study tried to provide guidelines how to deal with specific challenges of DOHS. We also provide initial evidence that the application of the proposed principles promises to reduce social tensions caused by the adoption of DOHS in organizational settings.

More concretely, in this paper we emphasized value tensions (privacy vs. wellbeing) as a social tension caused by of DOHS adoption in organizations. Since for legal reasons the organizational advantages (direct impact on lowering health-related costs and absenteeism, and indirect impact on employees' performance and productivity) depend upon employees' voluntary adoption, it is important to reduce any barriers that might prevent workers from accepting the technology. Widespread voluntary use is likely to occur incrementally, by gaining employees' trust, communicating the potential benefits, and reducing the privacy risk. This can be accomplished by embedding more social responses, as well as presence and fairness interventions within the system via technical and organizational features.

On the other hand, blurring the boundary between work and private life by asking employees to wear DOHS (or adopt similar technologies initially designed for consumer marketplaces such as social media and mobile apps) influences company structure. Our organizational and technological insights will help decision makers understand how to minimize role and activity tensions caused by this type of work/life integration. To avoid 
role tensions, employers should commit not only to providing devices but also to allocating an acceptable amount of time for employees to interact with the system. Systems designers should provide features for limiting access outside the acceptable range. However, even though active interaction (e.g., checking the dashboard, playing games, and other dedicated wellbeing features) can be limited, passive interaction (e.g., receiving alerts and recommendations) should not. Such passive interactions, though, should not interrupt employees' work activities. Therefore, grounded in our understanding of interruption evaluation paradigm (e.g., Grandhi \& Jones, 2010), we argue the need for two different levels of interruption management. One would feature automated reduction of excessive alerts based on an analysis of the user context and importance of the interruption. The second would give the employee full power to manage and control interruptions, when needed.

The findings of this study have implications for DOHS designers, as well. For designers, the proposed DOHS design principles could offer inspiration to creating more effective designs. While DOHS design principles offer a guideline from which actionable possibilities for DOHS users can be accomplished, designers must also have a certain amount of freedom to design and develop the systems as they see fit. Nevertheless, for each proposed principle, several possible technical features have also been recommended.

\subsection{Limitations and Future Work}

While our study lays a foundation for reducing social tensions caused by DOHS adoption in a work environment, this research has several limitations. Most notably, the proposed design principles are on a primarily conceptual level. The focus of this work was on the theoretical underpinnings of explanatory statements and design principles; while an actual DOHS implementation based on the proposed principles, was not covered in the study. Therefore, further research instantiating these principles to actual DOHS implementations will need to be undertaken. In addition, the evaluation of the proposed artefact (the design principles) was limited to an evaluation strategy to exploring the applicability of the principles in practice, based on systems designers and decision makers operating from an employer's perspective; this was to avoid any unnecessary costs before the actual implementation of an instantiated artefact, in a real context with real users. The other limitation of the evaluation in this study is focusing on exploring the applicability of principles on one working environment with white collar workers. 
Thus, future research should examine the applicability of principles in other work environments as well.

\section{$5 \quad$ Conclusion}

This paper following the DSR paradigm designs and evaluates DOHS principles to reduce the social tensions caused by adoption of such systems in organizational settings. To reduce the value tensions (privacy vs. wellbeing) the DOHS should support the social presence, fairness and response. To cope with action tensions (work vs. leisure activities) DOHS should feature the automated and manual interruption management. Finally, to deal with role tensions (leisure vs. work roles) DOHS should support the redefinition of stablished personal and structural role of employees at work environment in a way that fits to work/life role integration. The applicability of the principles is validated by means of two user groups of the principles: the system designers and managers adopting DOHS. These two groups are considered as the main users of the principles, since the principles derived in this study provide both organizational and technological insights to minimize social tensions caused by DOHS adoption in an organizational setting.

\section{References}

Ambrose, M., \& Alder, G. (2000). Designing, implementing, and utilizing computerized performance monitoring: Enhancing organizational justice. Research in Personnel and Human Resources Management, 18, 187-220.

Ara, K., Akitomi, T., Sato, N., Tsuji, S., Hayakawa, M., Wakisaka, Y., Ohkubo, N., Otsuka, R., Beniyama, F., Moriwaki, N., \& Yano, K. (2011). Healthcare of an organization: using wearable sensors and feedback system for energizing workers. In Proceedings of the 16th Asia and South Pacific Design Automation Conference (pp. 567-572). Yokohama, Japan: IEEE Press.

Baskerville, R. L., \& Pries-Heje, J. (2010). Explanatory Design Theory. Business \& Information Systems Engineering, 2, 271-282.

Beck, R., Weber, S., \& Gregory, R. W. (2013). Theory-generating design science research. Information Systems Frontiers, 15, 637-651.

Berry, L., Mirabito, A. M., \& Baun, W. B. (2010). What's the hard return on employee wellness programs? Harvard Business Review, December, 2012-2068. 
Bostrom, R. P. (1980). Role conflict and ambiguity: Critical variables in the MIS userdesigner relationship. In Proceedings of the 17th Annual Computer Personnel Research Conference (pp. 88-115). Miami, USA: ACM.

Carlsson, S. A., Henningsson, S., Hrastinski, S., \& Keller, C. (2011). Socio-technical IS design science research: developing design theory for IS integration management. Information Systems and e-Business Management, 9, 109-131.

Christophersen, M., Mørck, P., Langhoff, T. O., \& Bjørn, P. (2015). Unforeseen Challenges. In M. Antona \& C. Stephanidis (Eds.), Universal Access in HumanComputer Interaction. Access to Learning, Health and Well-Being: 9th International Conference, UAHCI 2015, Held as Part of HCI International 2015, Los Angeles, USA, Part III (pp. 288-299). Cham, Switzerland: Springer.

Cohen-Charash, Y., \& Spector, P. E. (2001). The role of justice in organizations: A metaanalysis. Organizational Behavior and Human Decision Processes, 86, 278-321.

Culnan, M. J., \& Armstrong, P. K. (1999). Information privacy concerns, procedural fairness, and impersonal trust: An empirical investigation. Organization Science, 10, 104-115.

Dabbish, L. A., \& Baker, R. S. (2003). Administrative assistants as interruption mediators. In Proceedings of the CHI'O3 Extended Abstracts on Human Factors in Computing Systems (pp. 1020-1021). Fort Lauderdale, USA: ACM.

De Leoz, G., \& Petter, S. (2018). Considering the social impacts of artefacts in information systems design science research. European Journal of Information Systems, 27, 154170.

Dvorak, J. L. (2008). Moving wearables into the mainstream: Taming the Borg. New York: Springer.

Feldstein, A., Simon, S. R., Schneider, J., Krall, M., Laferriere, D., Smith, D. H., Sittig, D. F., \& Soumerai, S. B. (2004). How to design computerized alerts to ensure safe prescribing practices. The Joint Commission Journal on Quality and Patient Safety, 30, 602-613.

Fingas, R. (2015). IBM adopts Apple Watch for internal fitness initiative \& Watson-linked health app. AppleInsider. Available: http://appleinsider.com/articles/15/10/27/ibmadopts-apple-watch-for-internal-fitness-initiative-watson-linked-health-app 
Fisher, C. D., \& Gitelson, R. (1983). A meta-analysis of the correlates of role conflict and ambiguity. Journal of Applied Psychology, 68, 320.

Folger, R., \& Bies, R. J. (1989). Managerial responsibilities and procedural justice. Employee Responsibilities and Rights Journal, 2, 79-90.

Giddens, L., Gonzalez, E., \& Leidner, D. (2016). I track, therefore I am: Exploring the impact of wearable fitness devices on employee identity and well-being. In Proceedings of the 22nd Americas Conference on Information Systems (pp. 1-5). San Diego, USA: AIS.

Goldkuhl, G. (2004). Design theories in information systems - A need for multigrounding. Journal of Information Technology Theory and Application, 6, 59-72.

Goldkuhl, G. (2012). From action research to practice research. Australasian Journal of Information Systems, 17, 57-78.

Goldkuhl, G., \& Lind, M. (2010). A Multi-Grounded Design Research Process. In R. Winter, J. L. Zhao \& S. Aier (Eds.), Global Perspectives on Design Science Research (pp. 45-60). Berlin, Heidelberg: Springer.

Gouldner, A. W. (1960). The norm of reciprocity: A preliminary statement. American Sociological Review, 25, 161-178.

Grandhi, S., \& Jones, Q. (2010). Technology-mediated interruption management. International Journal of Human-Computer Studies, 68, 288-306.

Greenberg, J. (1987). A taxonomy of organizational justice theories. Academy of Management Review, 12, 9-22.

Gregor, S. (2002). Design theory in Information Systems. Australasian Journal of Information Systems, 10, 14-22.

Gregor, S., \& Hevner, A. R. (2013). Positioning and presenting design science research for maximum impact. MIS Quarterly, 37, 337-355.

Gregor, S., \& Jones, D. (2007). The anatomy of a design theory. Journal of the Association for Information Systems, 8, 312-335.

Gregory, R. W., \& Muntermann, J. (2014). Heuristic theorizing: Proactively generating design theories. Information Systems Research, 25, 639-653. 
Guo, X., Zhang, X., \& Sun, Y. (2016). The privacy-personalization paradox in mHealth services acceptance of different age groups. Electronic Commerce Research and Applications, 16, 55-65.

Hackos, J. T., \& Redish, J. (1998). User and task analysis for interface design. New York, USA: John Wiley \& Sons.

Hall, D. T. (1972). A model of coping with role conflict: The role behavior of college educated women. Administrative Science Quarterly, 17, 471-486.

Hevner, A. R., \& Chatterjee, S. (2010). Design research in information systems: Theory and practice. Dordrecht, Heidelberg, London, New York: Springer.

Hevner, A. R., March, S. T., Park, J., \& Ram, S. (2004). Design science in information systems research. MIS Quarterly, 28, 75-105.

Iivari, J. (2015). Distinguishing and contrasting two strategies for design science research. European Journal of Information Systems, 24, 107-115.

Jackson, S. E., \& Schuler, R. S. (1985). A meta-analysis and conceptual critique of research on role ambiguity and role conflict in work settings. Organizational Behavior and Human Decision Processes, 36, 16-78.

Jonsson, K., Holmström, J., \& Lyytinen, K. (2009). Turn to the material: Remote diagnostics systems and new forms of boundary-spanning. Information and Organization, 19, 233-252.

Kärkkäinen, M., \& Holmström, J. (2002). Wireless product identification: enabler for handling efficiency, customisation and information sharing. Supply Chain Management: An International Journal, 7, 242-252.

Kritzler, M., Bäckman, M., Tenf, A., \& Michahelles, F. (2015). Wearable technology as a solution for workplace safety. In Proceedings of the 14th International Conference on Mobile and Ubiquitous Multimedia (pp. 213-217). Linz, Austria: ACM.

Kuechler, W., \& Vaishnavi, V. (2012). A framework for theory development in design science research: multiple perspectives. Journal of the Association for Information Systems, 13, 395-423.

Lavallière, M., Arezes, P., Burstein, A., \& Coughlin, J. (2015). The quantified-self and wearable technologies in the workplace: implications and challenges for their 
implementations. In Proceedings of the 2015 International Symposium on Occupational Safety and Hygiene (pp. 161-163): Guimarães, Portugal.

Lavallière, M., Burstein, A. A., Arezes, P., \& Coughlin, J. F. (2016). Tackling the challenges of an aging workforce with the use of wearable technologies and the quantified-self. DYNA, 83, 38-43.

Levinson, D. J. (1959). Role, personality, and social structure in the organizational setting. The Journal of Abnormal and Social Psychology, 58, 170-180.

Li, H., Wu, J., Gao, Y., \& Shi, Y. (2016). Examining individuals' adoption of healthcare wearable devices: An empirical study from privacy calculus perspective. International Journal of Medical Informatics, 88, 8-17.

Li, Y. (2012). Theories in online information privacy research: A critical review and an integrated framework. Decision Support Systems, 54, 471-481.

Lind, E. A., \& Tyler, T. R. (1988). The social psychology of procedural justice. New York: Plenum: Springer.

Maikala, R. V., Cavuoto, L. A., Maynard, W. S., Fox, R. R., Lin, J.-H., Liu, J., \& Lavallière, M. (2014). Aging, obesity and beyond implications for healthy work environment. In Proceedings of the Human Factors and Ergonomics Society Annual Meeting (pp. 1648-1652). Chicago, USA: Sage.

Mandviwalla, M. (2015). Generating and justifying design theory. Journal of the Association for Information Systems, 16, 314-344.

Marabelli, M., Hansen, S., Newell, S., \& Frigerio, C. (2017). The light and dark side of the black box: Sensor-based technology in the automotive industry. Communications of the Association for Information Systems, 40, 351-374.

Mark, G., Gudith, D., \& Klocke, U. (2008). The cost of interrupted work: more speed and stress. In Proceedings of the SIGCHI Conference on Human Factors in Computing Systems (pp. 107-110). Florence, Italy: ACM.

Markus, M. L., Majchrzak, A., \& Gasser, L. (2002). A design theory for systems that support emergent knowledge processes. MIS Quarterly, 26, 179-212.

Mathiassen, L., \& Nielsen, P. A. (2008). Engaged scholarship in IS research. Scandinavian Journal of Information Systems, 20, 3-20. 
Mathur, A., Broeck, M. V. d., Vanderhulst, G., Mashhadi, A., \& Kawsar, F. (2015). Tiny habits in the giant enterprise: understanding the dynamics of a quantified workplace. In Proceedings of the 2015 ACM International Joint Conference on Pervasive and Ubiquitous Computing (pp. 577-588). Osaka, Japan: ACM.

Mathur, A., Van den Broeck, M., Vanderhulst, G., Mashhadi, A., \& Kawsar, F. (2015). Quantified Workplace: Opportunities and Challenges. In Proceedings of the 13th International Conference on Mobile Systems, Applications, and Services (pp. 37-41). Florence, Italy: ACM.

Mettler, T. (2018). Contextualizing a professional social network for health care: Experiences from an action design research study. Information Systems Journal, 28, 684-707. https://doi.org/10.1111/isj.12154.

Mettler, T., \& Rohner, P. (2009). Situational maturity models as instrumental artifacts for organizational design. In Proceedigns of the 4 th International Conference on Design Science Research in Information Systems and Technology (pp. 1-9). Philadelphia, USA: ACM.

Mettler, T., \& Wulf, J. (2019). Physiolytics at the workplace: Affordances and constraints of wearables use from an employee's perspective. Information Systems Journal, 29, 245-273. https://doi.org/10.1111/isj.12205.

Milewski, A. E. (2006). Interruption management and telephone call screening. International Journal of Human-Computer Interaction, 20, 19-33.

Moore, P. V., \& Piwek, L. (2016). Regulating wellbeing in the brave new quantified workplace. Employee Relations, 39, 308-316.

Niehaves, B., \& Ortbach, K. (2016). The inner and the outer model in explanatory design theory: the case of designing electronic feedback systems. European Journal of Information Systems, 25, 303-316.

Nieuwenhuijsen, K., Bruinvels, D., Frings-Dresen, \& M. (2010). Psychosocial work environment and stress-related disorders, a systematic review. Occupational Medicine, 60, 277-286.

Olguín, D. O., Waber, B. N., Kim, T., Mohan, A., Ara, K., \& Pentland, A. (2009). Sensible organizations: Technology and methodology for automatically measuring 
organizational behavior. IEEE Transactions on Systems, Man, and Cybernetics, Part B: Cybernetics, 39, 43-55.

Olson, P. (2014). Wearable tech is plugging into health insurance. Forbes Magazine. Available: $\quad$ http://www.forbes.com/sites/parmyolson/2014/06/19/wearable-techhealth-insurance/

Pavlou, P. A. (2003). Consumer acceptance of electronic commerce: Integrating trust and risk with the technology acceptance model. International Journal of Electronic Commerce, 7, 101-134.

Peffers, K., Tuunanen, T., Rothenberger, M. A., \& Chatterjee, S. (2007). A design science research methodology for information systems research. Journal of Management Information Systems, 24, 45-77.

Pozzi, G., Pigni, F., \& Vitari, C. (2014). Explaining big sata impact on healthcare organizations: A technology affordance approach. In Proceedings of the 2013 Conference of the Italian Chapter of the Association of Information Systems (pp. 1-8). Milano, Italy: Springer.

Pries-Heje, J., Baskerville, R. L., \& Venable, J. R. (2008). Strategies for design science research evaluation. In Proceedings of the16th European Conference on Information Systems (pp. 255-266). Galway, Ireland: AIS.

Purao, S. (2002). Design research in the technology of information systems: Truth or dare. In GSU Department of CIS Working Paper (pp. 1-34). Atlanta: Georgia State University.

Ragu-Nathan, T., Tarafdar, M., Ragu-Nathan, B. S., \& Tu, Q. (2008). The consequences of technostress for end users in organizations: Conceptual development and empirical validation. Information Systems Research, 19, 417-433.

Reis, H. T., \& Shaver, P. (1988). Intimacy as an interpersonal process. Handbook of Personal Relationships, 24, 367-389.

Rizzo, J. R., House, R. J., \& Lirtzman, S. I. (1970). Role conflict and ambiguity in complex organizations. Administrative Science Quarterly, 15, 150-163.

Rosemann, M., \& Vessey, I. (2008). Toward improving the relevance of information systems research to practice: The role of applicability checks. MIS Quarterly, 32, 122. 
Sarker, S., \& Lee, A. S. (2002). Using a positivist case research methodology to test three competing theories-in-use of business process redesign. Journal of the Association for Information Systems, 2, 1-72.

Sein, M. K., Henfridsson, O., Purao, S., Rossi, M., \& Lindgren, R. (2011). Action design research. MIS Quarterly, 35, 37-56.

Short, J., Williams, E., \& Christie, B. (1976). The social psychology of telecommunications. Hoboken: John Wiley \& Sons.

Simon, H. A. (1996). The Sciences of the Artificial (3 ed.). Cambridge, London: MIT Press.

Ski, C. F., Thompson, D. R., \& Castle, D. J. (2016). Trialling of an optimal health programme (OHP) across chronic disease. Trials, 17, 445.

Sparks, K., Faragher, B., \& Cooper, C. L. (2001). Well-being and occupational health in the 21st century workplace. Journal of Occupational and Organizational Psychology, 74, 489-509.

Stewart, D. W., Shamdasani, P. N., \& Rook, D. W. (2007). Focus groups: Theory and practice (2 ed.). Thousand Oaks: Sage.

Stewart, J. (2006). Value conflict and policy change. Review of Policy Research, 23, 183195.

Sun, J., \& Qu, Z. (2015). Understanding health information technology adoption: A synthesis of literature from an activity perspective. Information Systems Frontiers, 17, 1177-1190.

Szóstek, A. M., \& Markopoulos, P. (2006). Factors defining face-to-face interruptions in the office environment. In Proceedings of the CHI'O6 Extended Abstracts on Human Factors in Computing Systems (pp. 1379-1384). Montreal, Canada: ACM.

Tremblay, M. C., Hevner, A. R., \& Berndt, D. J. (2010). The use of focus groups in design science research. In A. R. Hevner \& S. Chatterjee (Eds.), Design Research in Information Systems: Theory and Practice (pp. 121-143). Boston: Springer.

Truong, K. N., Hayes, G. R., \& Abowd, G. D. (2006). Storyboarding: an empirical determination of best practices and effective guidelines. In Proceedings of the 6th Conference on Designing Interactive Systems (pp. 12-21). University Park, USA: ACM. 
van Aken, J. E. (2004). Management research based on the paradigm of the design sciences: The quest for field-tested and grounded technological rules. Journal of Management Studies, 41, 219-246.

van Aken, J. E., \& Romme, G. (2009). Reinventing the future: adding design science to the repertoire of organization and management studies. Organization Management Journal, 6, 5-12.

Venable, J. R., Pries-Heje, J., \& Baskerville, R. L. (2016). FEDS: a framework for evaluation in design science research. European Journal of Information Systems, 25, 77-89.

Vyas, D., Fitz-Walter, Z., Mealy, E., Soro, A., Zhang, J., \& Brereton, M. (2015). Exploring physical activities in an employer-sponsored health program. In Proceedings of the 33rd Annual ACM Conference Extended Abstracts on Human Factors in Computing Systems (pp. 1421-1426). Seoul, South Korea: ACM.

Walls, J. G., Widmeyer, G. R., \& El Sawy, O. A. (1992). Building an information system design theory for vigilant EIS. Information Systems Research, 3, 36-59.

Wilson, J. R., \& Sharples, S. (2015). Evaluation of human work (4 ed.). Boca Raton: CRC Press.

Winter, R. (2008). Design science research in Europe. European Journal of Information Systems, 17, 470-475.

Winter, R., \& Baskerville, R. L. (2010). Science of business \& information systems engineering. Business \& Information Systems Engineering, 2, 269-270.

Wipfli, R., \& Lovis, C. (2010). Alerts in clinical information systems: building frameworks and prototypes. Studies in Health Technology and Informatics, 155, 163-169.

Zijlstra, F. R. H., Roe, R. A., Leonora, A. B., \& Krediet, I. (1999). Temporal factors in mental work: Effects of interrupted activities. Journal of Occupational and Oorganizational Psychology, 72, 163-185. 


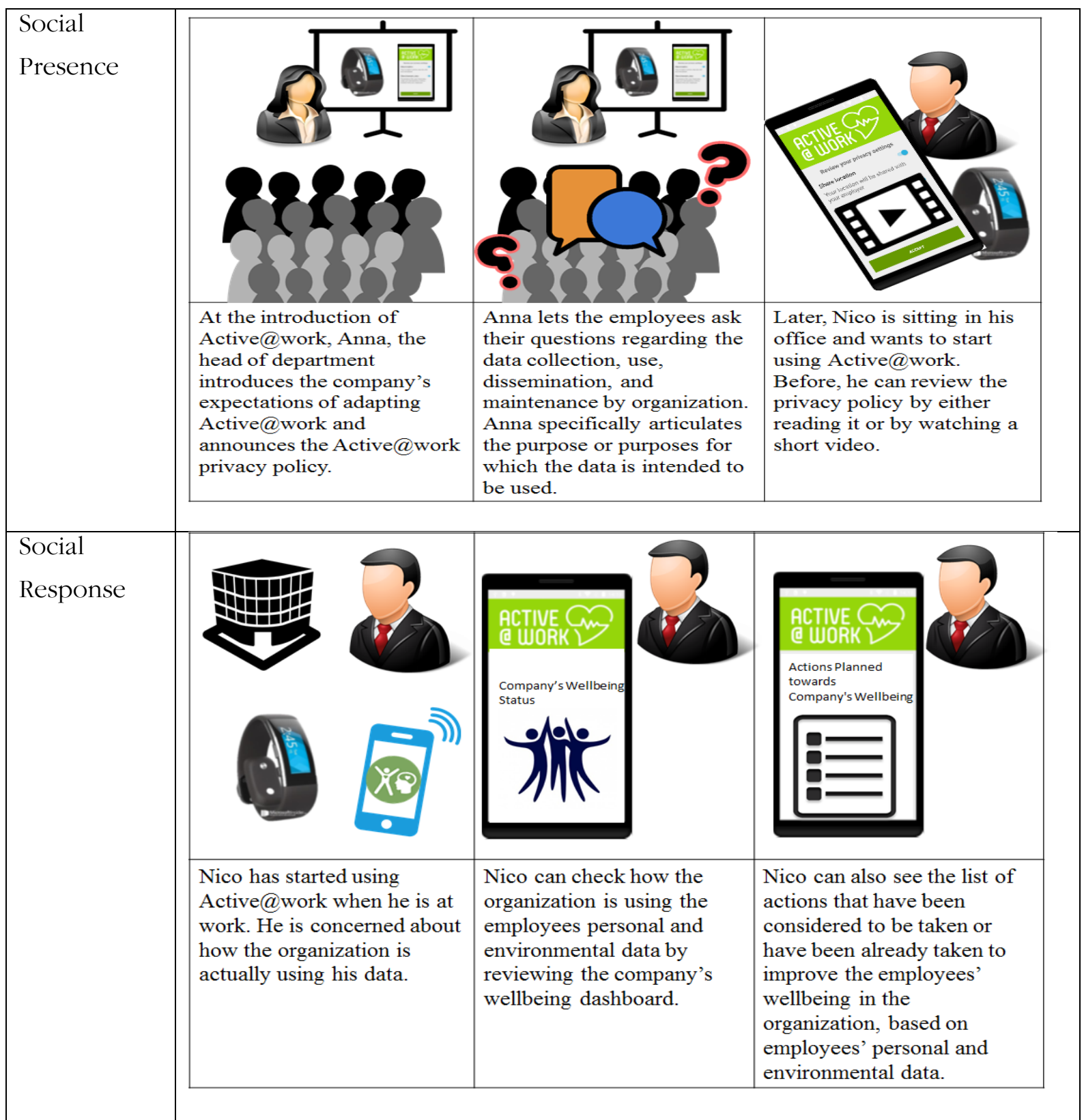




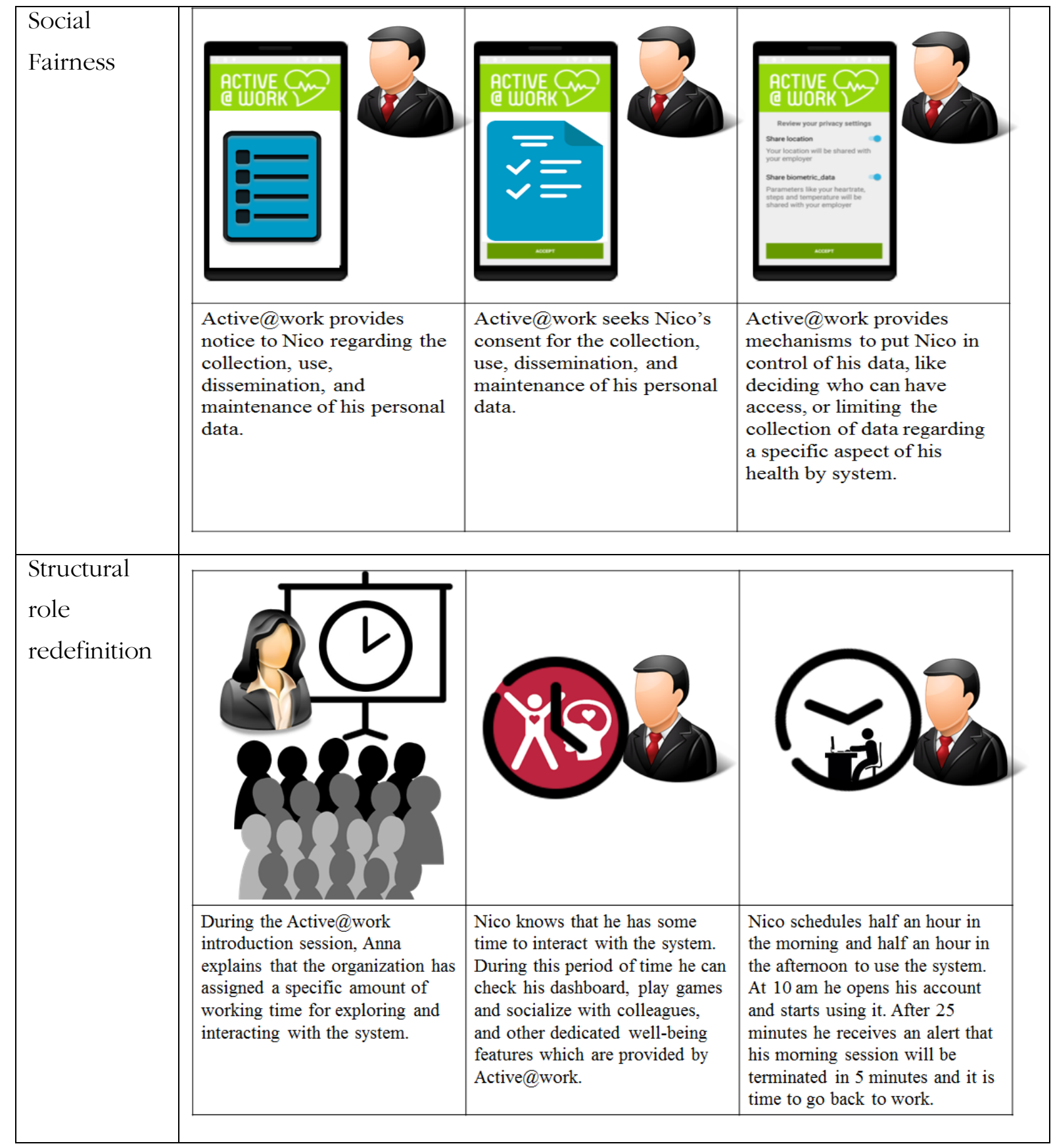




Automated
Interruption
management




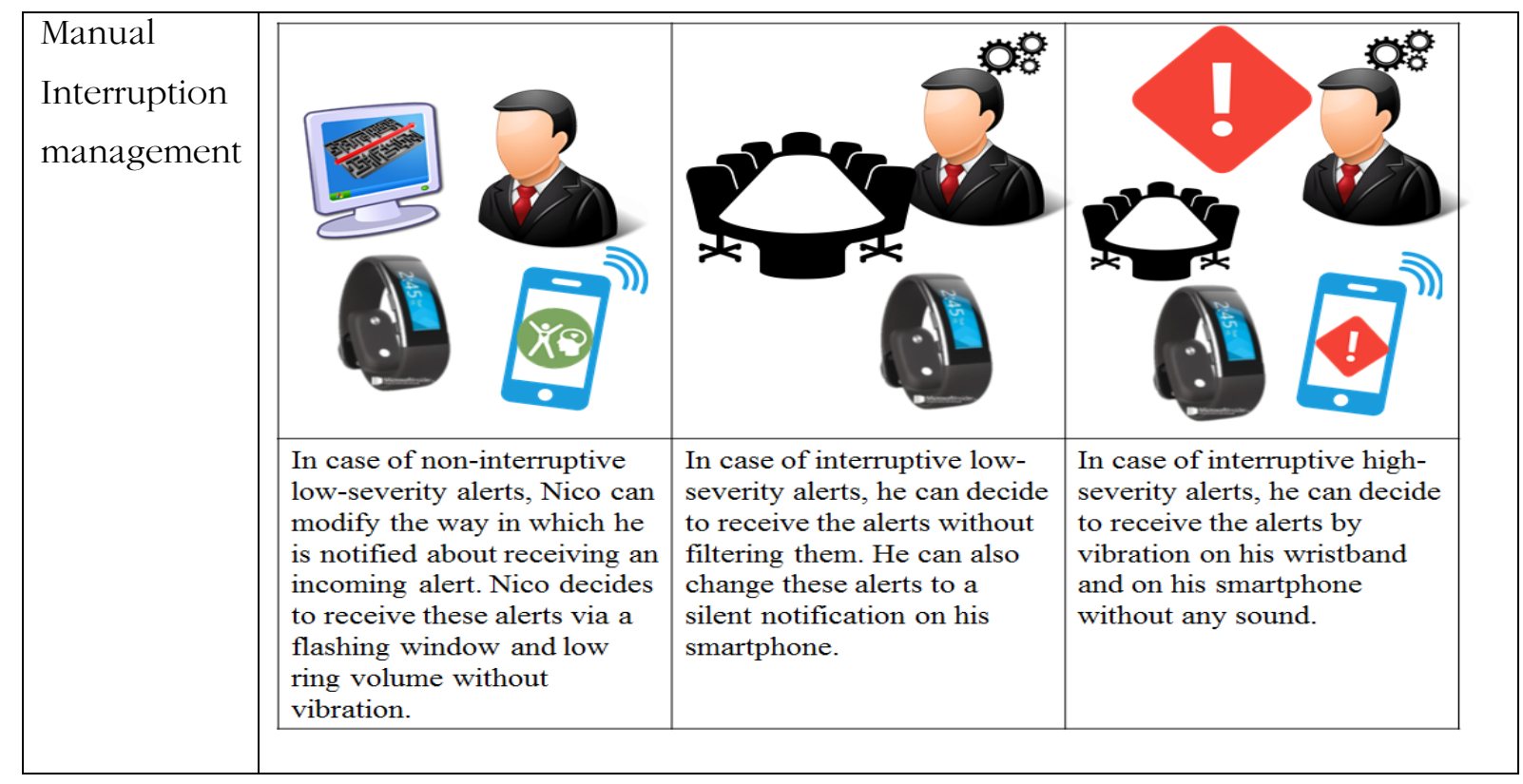

